\title{
Responses to Incremental Exercise and the Impact of the Coexistence of HF and COPD on Exercise Capacity: A Follow-up Study
}

\section{Polliana B. Dos Santos}

Federal University of Sao Carlos

\section{Rodrigo P. Simões}

Federal University of Alfenas

Cassia L. Goulart

Federal University of Sao Carlos

Guilherme P. T. Arêas

Federal University of Amazonas

Renan S. Marinho

Federal University of Sao Carlos

Patrícia F. Camargo

Federal University of Sao Carlos

Meliza G. Roscani

Federal University of Sao Carlos

\section{Renata F. Arbex}

Federal University of Sao Carlos

Cláudio R. Oliveira

Federal University of São Carlos - UFSCar

Renata G. Mendes

Federal University of Sao Carlos

\section{Ross Arena}

University of Illinois at Chicago

Audrey Borghi-silva ( $\square$ audreyborghi@gmail.com )

Federal University of Sao Carlos

\section{Research Article}

Keywords: heart failure, chronic obstructive pulmonary disease, overlap syndrome, cardiopulmonary exercise testing

Posted Date: August 6th, 2021 
DOI: https://doi.org/10.21203/rs.3.rs-757797/v1

License: (c) (1) This work is licensed under a Creative Commons Attribution 4.0 International License. Read Full License

Version of Record: A version of this preprint was published at Scientific Reports on January 31st, 2022. See the published version at https://doi.org/10.1038/s41598-022-05503-5. 


\section{Abstract}

Aim: Our aim was to evaluate: 1) the prevalence of coexistence of heart failure (HF) and chronic obstructive pulmonary disease (COPD) in the studied population; 2) the impact of HF+COPD on exercise performance and contrasting exercise responses in patients with only a diagnosis of HF or COPD; and 3) the relationship between clinical characteristics and measures of cardiorespiratory fitness; 4) verify the occurrence of cardiopulmonary events in the follow-up period of up to 24 months years.

Methods: The current study included 124 patients (HF:46, COPD: 53 and HF+COPD:25) that performed advanced pulmonary function tests, echocardiography, analysis of body composition by bioimpedance and symptom-limited incremental cardiopulmonary exercise testing (CPET) on a cycle ergometer. All patients were contacted by telephone every 6 months and questioned about exacerbations, hospitalizations for cardiopulmonary causes and death.

Results: We found a $20 \%$ prevalence of HF + COPD overlap in the studied population. Patients with $\mathrm{HF}+\mathrm{COPD}$ demonstrated a lower work rate (WR), peak oxygen uptake $\left(V^{\mathrm{O}} \mathrm{O}_{2}\right)$, rate pressure product (RPP), circulatory power (CP) and ventilatory power (VP) compared to those only diagnosed with HF and COPD. In addition, significant correlations were observed between lean mass and peak $\mathrm{VO}_{2}(r: 0.56 \mathrm{p}<0.001)$, the oxygen uptake efficiency slope (OUES) ( $r: 0.42 p<0.001)$, and $\mathrm{O}_{2}$ pulse ( $\mathrm{r}: 0.58 p<0.001$ ), lung diffusing factor for carbon monoxide ( $\left.D_{\mathrm{LCO}}\right)$ and WR (r: $\left.0.51 \mathrm{p}<0.001\right), \mathrm{D}_{\mathrm{LCO}}$ and VP (r: $0.40 \mathrm{p:}$ : 0.002), forced expiratory volume in first second $\left(\mathrm{FEV}_{1}\right)$ and peak $\mathrm{VO}_{2}(\mathrm{r}: 0.52 ; \mathrm{p}<0.001)$, and $\mathrm{FEV}_{1}$ and $\mathrm{WR}(\mathrm{r}: 0.62$; $p<0.001)$. There were no significant differences in the occurrence of events and deaths contrasting both groups.

Conclusion: the coexistence of HF+COPD induces greater impairment on exercise performance when compared to patients without overlapping diseases, however the overlap of the two diseases did not increase the probability of the occurrence of cardiopulmonary events and deaths when compared to groups with isolated diseases in the period studied. CPET provides important information to guide effective strategies for these patients with the goal of improving exercise performance and functional capacity. Moreover, given our findings related to pulmonary function, body composition and exercise responses, evidenced that the lean mass, $\mathrm{FEV}_{1}$ and $\mathrm{D}_{\mathrm{LCO}}$ influence important responses to exercise.

\section{Introduction}

The incidence and prevalence of chronic-degenerative diseases in a progressively elderly population has increased worldwide over the last several decades ${ }^{1}$. In this context, cardiopulmonary disease (CPD) is increasing and remains the leading cause of death in many countries; in Brazil, CPD is responsible for approximately $20 \%$ of all deaths in adults 30 years of age or older ${ }^{2,3}$.

Heart failure (HF) and chronic obstructive pulmonary disease (COPD) are predominant chronic diseases; the growing prevalence of $\mathrm{HF}$ and COPD reflects a combination of increasing incidence, an aging 
population, and improvements in the treatment of both diseases ${ }^{4,5,6}$. HF and COPD share similar signs and symptoms, and often coexist, leading to a worse prognosis, as well as greater challenges for diagnosis and the establishment of therapeutic interventions. It is estimated that the prevalence of $\mathrm{HF}$ in patients with COPD and vice versa is between $10 \%$ and $25 \%$ in developed countries ${ }^{7,8}$.

One of the most common and impactful symptoms in patients with either independent or overlapping HF and COPD is decreased exercise capacity; a commonly reported subjective symptom in dyspnea with exertion ${ }^{9,10}$. Therefore, a comprehensive assessment of exercise capacity is relevant in these patient populations from diagnostic, prognostic and therapeutic efficacy perspective.

Cardiopulmonary exercise testing (CPET) is the gold-standard approach to assessing exercise capacity and more broadly cardiorespiratory fitness; an evidence-based panel of core CPET measures allows for a more comprehensive evaluation ${ }^{11}$. Through CPET, ventilatory and gas exchange, as well as heart rate (HR), electrocardiogram, and blood pressures, are measured to provide detailed information on the cardiovascular, pulmonary, and muscular systems as well as detect the primary limitation to exercise in these chronic conditions ${ }^{12}$.

Both patients with HF and COPD have been studied extensively, but largely as separate and distinct clinical diagnoses. The coexistence of HF and COPD has important therapeutic and prognostic implications, the knowledge about the prevalence of the concomitance of these diseases is clinically relevant. Moreover, follow-up studies have contributed substantially to the understanding of disease progression, clinical outcomes, mortality, and use of resource in health, as both conditions are quite disabling, generating heightened concern when these conditions coexist.

In the present study, we hypothesized that HF+COPD would further deteriorate cardiorespiratory fitness compared to patients diagnosed with HF and COPD in isolation. We additionally hypothesized that there are relationships between clinical characteristics and CPET measures of cardiorespiratory fitness. The specific aims of this study was to assess: 1) the prevalence of HF and COPD overlap in the studied population; 2) the impact of the overlapping HF+COPD on exercise capacity and cardiorespiratory fitness and to contrast these measures in patients with either HF or COPD in isolation; and 3) the relationship between clinical characteristics and measures of cardiorespiratory fitness 4 ) verify the occurrence of exacerbations, hospitalizations and deaths in the follow-up period of up to 24 months.

\section{Methods}

\section{Study Design and Subjects}

This cross-sectional study was reported following recommendations of the Strengthening the Reporting of Observational Studies in Epidemiology (STROBE) statement ${ }^{13}$. Three-hundred fifteen patients were screened from 3 cardiology and pneumology outpatient clinics of the University Hospital of the Federal University of São Carlos, from 01 June 2017 to 30 December 2019. All patients who attended during this 
period with the diagnosis of HF with reduced or borderline ejection fraction (EF) and/or COPD were contacted by phone and was asked questions regarding diagnosis, clinical conditions, disease stability, drug optimization, and functional mobility. For all patients, eligibility criteria were: 1) age range of 40-85 years; 2) clinically stable for at least 3 months (i.e., no worsening of symptoms, exacerbation or decompensation); 3 ) no change in dose or change in medication for at least 3 months; 4) no hospitalizations for any cause for at least 3 months; and 5) absence of any condition that may affect exercise performance (e.g., anemia, neuromuscular disorders, or malignancies). Exclusion criteria included: 1) long-term $\mathrm{O}_{2}$ therapy; 2) musculoskeletal disease that would impact exercise performance (e.g., osteoarthritis, osteonecrosis, trauma, etc.); and 3) peripheral arterial disease associated with claudication. Moreover, HF or COPD exacerbation or hospitalization during the study was a criterion for study drop-out. All patients who met the eligibility criteria were invited for an initial assessment and tests to confirm the diagnosis of one (HF or COPD) or both (HF+COPD) diseases being assessed in the current study.

Disease treatment was optimized before study entry and patients underwent CPET only after an agreement had been reached between pneumologists and cardiologists regarding disease stability. As showed in Figure 1, 124 patients with a confirmed diagnosis of HF and/or COPD were included. The Study followed the resolution no. 466 of the National Health Council (current guideline in Brazil) and The Declaration of Helsinki and was approved by the Ethics and Research Committee of the Federal University of São Carlos. All participants were informed about the objectives, experimental procedures and potential risks involved in this study and gave written informed consent statement prior to participation.

\section{Cardiac and Lung function Assessments}

All patients underwent a transthoracic two-dimensional and Doppler echocardiographic (HD11 XE, Philips, Amsterdam, Netherlands) examination at baseline to confirm the diagnosis, stratify the degree of systolic dysfunction, and obtain the necessary measures for cardiac function in the HF and HF+COPD groups and confirm the absence of reduced ejection fraction in the COPD group. Patients with HF were determined according to left ventricle ejection fraction $\leq 50 \%{ }^{14}$. Advanced pulmonary function assessment (Masterscreen Body, Mijnhardt/Jäger, Würzburg, German) was performed to obtain dynamic and static lung volumes and capacities, such us Forced Expiratory Volume in $1 \mathrm{~s}\left(\mathrm{FEV}_{1}\right)$, Forced Vital Capacity (FVC), Residual Volume (RV), Total Lung Capacity (TLC), Inspiratory Capacity (IC), and Diffusion Capacity Carbon Monoxide $\left(D_{\mathrm{LCO}}\right)$ pre and post-bronchodilator therapy. The GOLD criteria [postbronchodilator $\mathrm{FEV}_{1} / \mathrm{FVC}$ ratio < 0.70 ] was used to confirm a COPD diagnosis ${ }^{15}$.

\section{Cardiopulmonary exercise testing}


All patients underwent a symptom-limited CPET on an electronically braked cycle ergometer (Corival Recumbent, Lode, Groningen, Netherlands) using the Oxycon Mobile System (Mijnhardt/Jäger, Würzburg, German). The exercise protocol started with 5 min of data collection at rest, followed by unloaded cycling for $1 \mathrm{~min}$ with a subsequent increment of 5-10 watts each minute (ramp protocol). Patients were instructed to pedal at the cadence of 60 rotation per minute and the work rate (WR) increment was individually selected according to reported exercise tolerance. Breath-by-breath $\mathrm{VO}_{2}(\mathrm{~L} / \mathrm{min}), V \mathrm{CO}_{2}$ $(\mathrm{L} / \mathrm{min})$, and $V_{\mathrm{E}}(\mathrm{L} / \mathrm{min})$ were recorded. The CPET variables were reported as 20 -second averaged data. During the exercise test, $\mathrm{HR}$, twelve-lead electrocardiogram (ECG), blood pressure (BP), and arterial oxygen saturation were monitored. Arterial oxygen saturation was measured non-invasively by pulse oximetry $\left(\mathrm{SpO}_{2}, \%\right)$. Breathlessness and leg effort scores were rated according to the 10-point Borg category ratio ${ }^{16}$. Established exercise test termination criteria were followed and included angina (score above 2 on a scale of 0-10), life-threatening arrhythmias, electrocardiographic evidence of ischemia, a drop in systolic blood pressure, or arterial oxygen saturation $\leq 84 \%$ were considered to interrupt the test ${ }^{17}$. Key CPET variables were calculated for all patients as previously described. The $V_{\mathrm{E}} / V \mathrm{CO}_{2}$ slope was obtained through linear regression analysis ${ }^{18}$. Additionally, the linear relationship between oxygen uptake and the log transformation of $V_{E}$ (OUES) was calculated using the following equation: $V_{2}=$ a log $\mathrm{V}_{\mathrm{E}}+\mathrm{b}$, with the constant ' $\mathrm{a}$ ' referring to the rate of increase of $\mathrm{VO}_{2}{ }^{19}$. Circulatory power (CP) was obtained through the product of peak $\mathrm{VO}_{2}$ and peak systolic blood pressure and Ventilatory Power (VP) was calculated by dividing peak systolic blood pressure by the $V_{\mathrm{E}} / \mathrm{VCO}_{2}$ slope ${ }^{20,21}$.

\section{Patients follow-up}

All patients were followed for 24 months. The follow-up of patients was carried out through telephone contact every six months, where the patient or caregiver (in case the patient was unable to respond) answered a questionnaire with information regarding occurrence of cardiopulmonary events such as diseases exacerbations, hospitalizations by cardiopulmonary causes [acute myocardial infarction (AMI), stroke, cardiac or pulmonary surgery] and death.

\section{Statistical analysis}

A sample calculation was performed (GPower 3.1- University of Kiel, Kiel, Germany) using the peak $\mathrm{VO}_{2}$ obtained in pilot studies previously performed in our laboratory with individuals who were diagnosed with HF and COPD. From this sample calculation, 42 subjects, 14 for each group, were needed to reach sufficient statistical power (1- $\beta$ err prob) of 0.80 . The Shapiro-Wilk test was used to verify the data distribution. Descriptive variables were expressed as mean \pm standard deviation, when normal distribution was present, or median and interquartile, when non-normal distribution was not present. Categorical variables are expressed as frequencies and percentages and compared using the chi-square test. A one-way ANOVA was used to compare anthropometric measures, cardiac and pulmonary function 
measures and CPET measures. A two-way ANOVA was used to compare the exercises responses between groups at different times of exercise. Relationships between measures collected in the current study were assessed by the Pearson Correlation coefficient which correlation strengths will be classified as trivial $<0.1$, small $-0.30-0.50$, large $-0.50-0.70$, very large $->0.70-0.90$, nearly perfect $->0.90^{22}$. The analysis of the occurrence of events: number of disease exacerbations, number of hospitalizations for cardiopulmonary causes in the period, onset of AMI, stroke, cardiac or pulmonary surgery and death from cardiopulmonary causes was evaluated by the analysis of Klapan-Meier survival with the groups being compared using the Log-rank test. A p-value $<0.05$ was considered as statistically significant for all tests. All statistical analyses were performed using the Statistical Package for the Social Sciences (SPSS) 20.0 (IBM, Armonk, New York) and PRISM 9.0 (GraphPad, San Diego, California).

\section{Results}

\section{Clinical and resting characteristics}

Figure 2 demonstrates that the prevalence of coexisting HF and COPD diagnoses in the studied population was $20 \%$. Of the 25 patients who were included in the HF + COPD group, only 18 patients $(72 \%)$ had a previous diagnosis of overlap, while $7(28 \%)$ patients were diagnosed with the overlap after performing the echocardiogram or advanced pulmonary assessment in our study. The 7 patients where a diagnosis of HF or COPD was newly identified were referred for medication optimization and, after 3 months, returned to complete data collection for the current study.

Patient characteristics are reported in Table 1. Significant differences were found for most anthropometric and clinical variables amongst HF, COPD and HF + COPD groups. Most patients in both groups were male while patients in the COPD and HF + COPD groups were older $(p<0.05)$. In relation to cardiac function, as expected, patients with COPD presented with preserved systolic function, while in the $\mathrm{HF}$ and HF + COPD demonstrated similar levels of systolic dysfunction, although differences between HF and HF + COPD groups were found in systolic dysfunction staging $(p<0.05)$. Differences were found in the Mitral E wave in the HF and COPD groups. As expected, COPD and HF + COPD patients showed evidence of an obstructive ventilatory disorder. The frequency of patients in stage 2 according to the GOLD guidelines was greater in the COPD group. HF patients showed lower static lung volumes when compared to the COPD group ( $p<0.05)$; differences were also found in Residual volume (RV), \% predicted TLC and $\mathrm{D}_{\mathrm{LCO}}$. Comorbidities the most common in the HF group with hypertension being the most frequent comorbidity. 
Table 1

Anthropometric and clinical characteristics of studied subjects.

\begin{tabular}{|c|c|c|c|c|}
\hline \multirow[t]{2}{*}{ Variables } & HF & COPD & HF + COPD & $p$ \\
\hline & $n=46$ & $n=53$ & $n=25$ & \\
\hline Age, years & $60 \pm 8$ & $65 \pm 7^{*}$ & $68 \pm 7^{*}$ & $<0.000$ \\
\hline Gender, M/F (n) & $32 / 14$ & $37 / 16$ & $25 / 0$ & 0.007 \\
\hline Height, m & $1.66 \pm 0.93$ & $1.66 \pm 0.26$ & $1.75 \pm 0.1^{\star \#}$ & $<0.000$ \\
\hline Weight, kg & $80 \pm 16$ & $69 \pm 15^{*}$ & $71 \pm 14$ & 0.003 \\
\hline $\mathrm{BMI}, \mathrm{kg} / \mathrm{m}^{2}$ & $29 \pm 6$ & $25 \pm 4^{*}$ & $25 \pm 4^{*}$ & 0.002 \\
\hline Lean mass, \% & $50 \pm 10$ & $42 \pm 8^{*}$ & $48 \pm 9$ & 0.02 \\
\hline Fat-free mass, \% & $53 \pm 10$ & $45 \pm 8^{*}$ & $51 \pm 10$ & 0.01 \\
\hline Body fat, $\%$ & $26 \pm 9$ & $20 \pm 9$ & $19 \pm 8$ & 0.06 \\
\hline Protein, \% & $10.4 \pm 2$ & $8 \pm 1^{*}$ & $10.1 \pm 2$ & 0.02 \\
\hline Minerals, \% & $3.6 \pm 0.7$ & $2.9 \pm 0.5^{*}$ & $3.4 \pm 0.7$ & 0.005 \\
\hline \multicolumn{5}{|l|}{ Cardiac Function } \\
\hline Ejection Fraction, \% & $40 \pm 7$ & $70 \pm 8^{*}$ & $38 \pm 8^{\#}$ & $<0.000$ \\
\hline Mild/Moderate/Severe LV dysfunction (n) & $26 / 17 / 3$ & - & $10 / 11 / 4$ & $<0.000$ \\
\hline Indexed LA volume, $\mathrm{ml} / \mathrm{m}^{2}$ & $39 \pm 18$ & $36 \pm 13$ & $44 \pm 11$ & 0.21 \\
\hline Mitral E wave, cm/sec & $76 \pm 24$ & $63 \pm 14^{*}$ & $68 \pm 25$ & 0.03 \\
\hline Mitral e' wave, $\mathrm{cm} / \mathrm{sec}$ & $7 \pm 2$ & $9 \pm 2$ & $7 \pm 5$ & 0.30 \\
\hline E/e' ratio. $\mathrm{cm} / \mathrm{sec}$ & $11 \pm 7$ & $8 \pm 3$ & $10 \pm 6$ & 0.11 \\
\hline RVD, mm & $33(30-44)$ & $32(25-37)$ & $33(31-41)$ & 0.14 \\
\hline
\end{tabular}

Used ANOVA one way for continuous variables and used chi-square test for categorical variables; HF: Heart Failure, COPD: Chronic Obstructive Pulmonary Disease, M: male, F: Female, BMI: Body Mass Index, LV: Left ventricle, LA: Left atrium, RVD: Right ventricle diameter, $\mathrm{FEV}_{1}$ : Forced Expiratory Volume in 1s, FVC: Forced Vital Capacity, RV: Residual Volume, TLC: Total Lung Capacity, IC: Inspiratory Capacity, DLCO: Diffusion Capacity Carbon Monoxide NYHA: New York Heart Association, mMrc: modified Medical Research Council scale, DM: Diabetes mellitus, Cl: Coronary insufficiency, OSA: obstructive sleep apnea. Patients that peformed DLCO: 58 (HF:28, COPD:20, HF + COPD:10)

* Significant difference $(p<0.05)$ in relation to the HF group.

\# Significant difference $(p<0.05)$ in relation to the COPD group. 


\begin{tabular}{|c|c|c|c|c|}
\hline \multirow[t]{2}{*}{ Variables } & HF & COPD & $\mathrm{HF}+\mathrm{COPD}$ & $p$ \\
\hline & $n=46$ & $n=53$ & $\mathrm{n}=\mathbf{2 5}$ & \\
\hline \multicolumn{5}{|l|}{ Pulmonary Function } \\
\hline $\mathrm{FEV}_{1}, \mathrm{~L} / \mathrm{s}$ & $2.55 \pm 0.7$ & $1.38 \pm 0.9$ & $2.00 \pm 0.6$ & 0.49 \\
\hline $\mathrm{FEV}_{1}, \%$ predicted & $84 \pm 20$ & $54 \pm 21^{*}$ & $65 \pm 25^{*}$ & $<0.000$ \\
\hline FVC, L/s & $3.31 \pm 0.9$ & $2.80 \pm 2$ & $3.40 \pm 0.8$ & 0.65 \\
\hline FVC, \% predicted & $89 \pm 16$ & $79 \pm 25$ & $87 \pm 22$ & 0.05 \\
\hline $\mathrm{FEV}_{1} / \mathrm{FVC}, \mathrm{L} / \mathrm{s}$ & $0.78 \pm 0.7$ & $0.52 \pm 0.1^{\star}$ & $0.59 \pm 0.1^{*}$ & 0.03 \\
\hline RV, L & $2.6 \pm 1.1$ & $3.9 \pm 1.7^{\star}$ & $3.3 \pm 1.0$ & 0.004 \\
\hline $\mathrm{RV}, \%$ predicted & $127 \pm 49$ & $203 \pm 93^{*}$ & $143 \pm 44$ & $<0.000$ \\
\hline TLC, L & $5.2 \pm 1.6$ & $6.0 \pm 1.7$ & $5.9 \pm 1.3$ & 0.19 \\
\hline TLC, \% predicted & $88 \pm 24$ & $112 \pm 36^{*}$ & $99 \pm 30$ & 0.01 \\
\hline $\mathrm{RV} / \mathrm{TLC}$ & $0.48 \pm 0.12$ & $0.65 \pm 0.15^{*}$ & $0.55 \pm 0.11$ & $<0.000$ \\
\hline IC, L & $1.9 \pm 0.8$ & $1.6 \pm 0.8$ & $1.3 \pm 0.5$ & 0.08 \\
\hline IC, \% predicted & $75 \pm 32$ & $70 \pm 25$ & $51 \pm 19$ & 0.07 \\
\hline DLCO, mL/ mim/ mmHg & $20 \pm 5$ & $13 \pm 5^{\star}$ & $17 \pm 6$ & 0.001 \\
\hline DLCO, \% predicted & $82 \pm 13$ & $61 \pm 23^{*}$ & $72 \pm 20$ & 0.002 \\
\hline GOLD Stage, I/II/III/IV & - & $7 / 28 / 14 / 4$ & $9 / 11 / 5 / 0$ & $<0.000$ \\
\hline Pack/years & $40 \pm 33$ & $83 \pm 77^{*}$ & $59 \pm 30$ & 0.005 \\
\hline \multicolumn{5}{|l|}{ Functional Classification } \\
\hline NYHA, I/II/II/IV & $20 / 20 / 6 / 0$ & - & $8 / 11 / 6 / 0$ & 0.70 \\
\hline
\end{tabular}

Used ANOVA one way for continuous variables and used chi-square test for categorical variables; HF: Heart Failure, COPD: Chronic Obstructive Pulmonary Disease, M: male, F: Female, BMl: Body Mass Index, LV: Left ventricle, LA: Left atrium, RVD: Right ventricle diameter, $\mathrm{FEV}_{1}$ : Forced Expiratory Volume in 1s, FVC: Forced Vital Capacity, RV: Residual Volume, TLC: Total Lung Capacity, IC: Inspiratory Capacity, DLCO: Diffusion Capacity Carbon Monoxide NYHA: New York Heart Association, mMrc: modified Medical Research Council scale, DM: Diabetes mellitus, Cl: Coronary insufficiency, OSA: obstructive sleep apnea. Patients that peformed DLCO: 58 (HF:28, COPD:20, HF + COPD:10)

* Significant difference $(p<0.05)$ in relation to the HF group.

\# Significant difference $(p<0.05)$ in relation to the COPD group. 


\begin{tabular}{|c|c|c|c|c|}
\hline \multirow[t]{2}{*}{ Variables } & \multirow{2}{*}{$\begin{array}{l}\text { HF } \\
n=46\end{array}$} & \multirow{2}{*}{$\begin{array}{l}\text { COPD } \\
n=53\end{array}$} & \multirow{2}{*}{$\begin{array}{l}\mathrm{HF}+\mathrm{COPD} \\
\mathrm{n}=\mathbf{2 5}\end{array}$} & \multirow[t]{2}{*}{$p$} \\
\hline & & & & \\
\hline mMRC, 0/I/II/III/IV & - & $10 / 24 / 11 / 4 / 4$ & $4 / 12 / 5 / 1 / 3$ & 0.92 \\
\hline \multicolumn{5}{|l|}{ Comorbities } \\
\hline Hypertension, n (\%) & 33 & 31 & $22^{* \#}$ & 0.01 \\
\hline DM, n (\%) & $15^{\#}$ & 2 & $11^{\#}$ & $<0.000$ \\
\hline $\mathrm{Cl}, \mathrm{n}(\%)$ & 8 & $5^{*}$ & $5^{*}$ & 0.005 \\
\hline OSA, n (\%) & $4^{\#}$ & 18 & $1^{\#}$ & 0.001 \\
\hline Dyslipidemia, n(\%) & $19^{\#}$ & 8 & $15^{\#}$ & $<0.000$ \\
\hline Other, n (\%) & 28 & 23 & 15 & 0.19 \\
\hline Comorbities per patients, n (\%) & $3.2 \pm 1$ & $2.0 \pm 1^{*}$ & $3.0 \pm 1$ & 0.001 \\
\hline \multicolumn{5}{|l|}{ Medications } \\
\hline Betablockers, n & 46 & - & 24 & $<0.000$ \\
\hline Bronchodilator, $\mathrm{n}$ & $1^{\#}$ & 53 & 21 & $<0.000$ \\
\hline Antihypertensive, $\mathrm{n}$ & $38^{\#}$ & 50 & $20^{\#}$ & $<0.000$ \\
\hline Diuretics, n & 35 & $40^{*}$ & 24 & $<0.000$ \\
\hline \multicolumn{5}{|c|}{$\begin{array}{l}\text { Used ANOVA one way for continuous variables and used chi-square test for categorical variables; HF: } \\
\text { Heart Failure, COPD: Chronic Obstructive Pulmonary Disease, M: male, F: Female, BMI: Body Mass } \\
\text { Index, LV: Left ventricle, LA: Left atrium, RVD: Right ventricle diameter, FEV }{ }_{1} \text { : Forced Expiratory Volume } \\
\text { in 1s, FVC: Forced Vital Capacity, RV: Residual Volume, TLC: Total Lung Capacity, IC: Inspiratory } \\
\text { Capacity, DLCO: Diffusion Capacity Carbon Monoxide NYHA: New York Heart Association, mMrc: } \\
\text { modified Medical Research Council scale, DM: Diabetes mellitus, Cl: Coronary insufficiency, OSA: } \\
\text { obstructive sleep apnea. Patients that peformed DLCO: } 58 \text { (HF:28, COPD:20, HF + COPD:10) }\end{array}$} \\
\hline \multicolumn{5}{|c|}{ * Significant difference $(p<0.05)$ in relation to the HF group. } \\
\hline \# Significant difference $(p<0.0$ & the $\mathrm{CO}$ & oup. & & \\
\hline
\end{tabular}

\section{Metabolic, Cardiovascular and Ventilatory responses to Exercise}

Table 2 lists the responses to the CPET and the comparisons between groups. The WR and $\mathrm{VO}_{2}$ at peak exercise were significantly lower in the HF + COPD group when compared to the HF group $(p<0.05)$. 
Similar ventilatory responses were found between groups; however, the COPD group had higher $\mathrm{V}_{\mathrm{E}} / \mathrm{VCO}_{2}$ intercept values compared to the other groups. Ventilatory power (PV) was significantly higher in the COPD group when compared to the HF + COPD group $(p<0.05)$. However, the COPD group demonstrated a significantly lower $\mathrm{O}_{2}$ pulse compared to the HF group $(p<0.05)$. The HR recovery was worse in the COPD group when compared to the HF group, and in relation to systolic and diastolic BP at peak exercise, the HF + COPD group presented lower values compared to the other groups $(p<0.05)$. 
Table 2

Comparison between group responses to incremental CPET.

\begin{tabular}{|c|c|c|c|c|}
\hline \multirow[t]{2}{*}{ Variables } & \multirow{2}{*}{$\begin{array}{l}H F \\
n=46\end{array}$} & \multirow{2}{*}{$\begin{array}{l}\text { COPD } \\
\mathrm{N}=53\end{array}$} & \multirow{2}{*}{$\begin{array}{l}\mathrm{HF}+\text { COPD } \\
\mathrm{n}=\mathbf{2 5}\end{array}$} & \multirow[t]{2}{*}{$p$} \\
\hline & & & & \\
\hline Work rate, Watts & $75 \pm 32$ & $61 \pm 34$ & $54 \pm 21^{*}$ & 0.02 \\
\hline \multicolumn{5}{|l|}{ Metabolic responses } \\
\hline$V O_{2 \text { predicted, }} \mathrm{mL} \cdot \mathrm{min}$ & $1891 \pm 352$ & $1625 \pm 269^{*}$ & $1586 \pm 296^{*}$ & $<0.000$ \\
\hline$V O_{2 \text { peak, }}, \mathrm{mL} \cdot \mathrm{min}$ & $1011 \pm 414$ & $859 \pm 228$ & $806 \pm 300^{*}$ & 0.02 \\
\hline$V O_{2} \%$ of predicted, $\%$ & $53 \pm 16$ & $53 \pm 14$ & $51 \pm 15$ & 0.81 \\
\hline$V O_{2 \text { peak, }}, \mathrm{ml} \cdot \mathrm{kg}^{-1} \cdot \mathrm{min}^{-1}$ & $12.5 \pm 3$ & $12.3 \pm 3$ & $12.1 \pm 3$ & 0.88 \\
\hline $\mathrm{VO}_{2} / \mathrm{WR}, \mathrm{mL} \cdot \mathrm{min} . \mathrm{W}$ & $14 \pm 4$ & $16 \pm 7$ & $15 \pm 5$ & 0.20 \\
\hline$V \mathrm{CO}_{2}, \mathrm{~mL} \cdot \mathrm{min}$ & $1127 \pm 430$ & $908 \pm 371^{*}$ & $732 \pm 306^{*}$ & 0.001 \\
\hline $\mathrm{RER}_{\text {peak }}$ & $1.08 \pm 0.1$ & $1.04 \pm 0.1$ & $1.05 \pm 0.09$ & 0.12 \\
\hline \multicolumn{5}{|l|}{ Cardiovascular responses } \\
\hline $\mathrm{HR}_{\text {rest }}, \mathrm{bpm}$ & $72 \pm 10$ & $75 \pm 10$ & $79 \pm 16$ & 0.09 \\
\hline $\mathrm{HR}_{\text {maximal, }} \mathrm{bpm}$ & $168 \pm 8$ & $154 \pm 7^{\star}$ & $151 \pm 7^{\star}$ & $<0.000$ \\
\hline $\mathrm{HR}_{\text {peak }}, \mathrm{bpm}$ & $118 \pm 21$ & $120 \pm 17$ & $110 \pm 25$ & 0.13 \\
\hline $\mathrm{HR}$ \% of maximal & $73 \pm 12$ & $77 \pm 12$ & $72 \pm 17$ & 0.25 \\
\hline $\mathrm{HR}_{\text {rec }}, \mathrm{bpm}$ & $101 \pm 22$ & $110 \pm 18$ & $102 \pm 22$ & 0.09 \\
\hline$\Delta \mathrm{HR}_{\mathrm{rec}}, \mathrm{bpm}$ & $17 \pm 17$ & $8 \pm 9^{*}$ & $13 \pm 18$ & 0.02 \\
\hline $\mathrm{SBP}_{\text {rest }}, \mathrm{mmHg}$ & $122 \pm 14$ & $133 \pm 14^{*}$ & $119 \pm 22^{\#}$ & $<0.000$ \\
\hline
\end{tabular}

Used ANOVA one way; HF: Heart Failure, COPD: Chronic Obstructive Pulmonary Disease; $\mathrm{VO}_{2}$ : Oxygen uptake; $\mathrm{VCO}_{2}$ : Carbon dioxide output, RER: Respiratory exchange ratio; HR: Heart rate, SBP: Systolic Blood Pressure, DBP: Diastolic Blood Pressure, RPP: rate-pressure product, CP: circulatory power, VE: Ventilation, MVV: Maximal Voluntary Ventilation, $\mathrm{VE} / \mathrm{VCO}_{2}$ slope: Linear relation between minute ventilation and carbon dioxide output; OUES: Linear relationship between oxygen uptake and minute ventilation, VP: Ventilatory Power; $\mathrm{SaO}_{2}$ : peripheral saturation of $\mathrm{O}_{2}$.

* Significant difference $(p<0.05)$ in relation to the HF group.

\# Significant difference $(p<0.05)$ in relation to the COPD group. 


\begin{tabular}{|c|c|c|c|c|}
\hline \multirow[t]{2}{*}{ Variables } & HF & COPD & $\mathrm{HF}+\mathrm{COPD}$ & \multirow[t]{2}{*}{$p$} \\
\hline & $n=46$ & $N=53$ & $\mathrm{n}=25$ & \\
\hline $\mathrm{DBP}_{\text {rest }}, \mathrm{mmHg}$ & $79 \pm 10$ & $83 \pm 10$ & $77 \pm 11^{\#}$ & 0.03 \\
\hline $\mathrm{SBP}_{\text {peak, }}, \mathrm{mmHg}$ & $190 \pm 31$ & $198 \pm 28$ & $169 \pm 43^{\star \#}$ & 0.003 \\
\hline $\mathrm{DBP}_{\text {peak }}, \mathrm{mmHg}$ & $107 \pm 15$ & $104 \pm 17$ & $97 \pm 23$ & 0.08 \\
\hline Peak $\mathrm{O}_{2}$ pulse, $\mathrm{mL} /$ beat & $8.5 \pm 3$ & $7.1 \pm 2^{*}$ & $7.7 \pm 3$ & 0.05 \\
\hline $\mathrm{RPP}, \mathrm{bpm} \cdot \mathrm{mmHg}$ & $22238 \pm 6875$ & $24041 \pm 5730$ & $19090 \pm 7713^{\#}$ & 0.01 \\
\hline CP, mmHg.ml.kg-1 $\mathrm{min}^{-1}$ & $2439 \pm 857$ & $2451 \pm 741$ & $1987 \pm 685^{\#}$ & 0.03 \\
\hline \multicolumn{5}{|l|}{ Ventilatory responses } \\
\hline$V_{\text {E peak, }}$ L.min & $43(35-54)$ & $36(28-44)$ & $36(26-51)$ & 0.07 \\
\hline$V_{\mathrm{E}} / \mathrm{VCO}_{2}$ slope & $37 \pm 10$ & $35 \pm 11$ & $38 \pm 13$ & 0.51 \\
\hline$V_{\mathrm{E}} / \mathrm{VCO}_{2}$ intercept, $\mathrm{L} /$ minute & $1.0 \pm 2$ & $3.0 \pm 3^{*}$ & $0.7 \pm 2 \#$ & 0.001 \\
\hline OUES & $1.3 \pm 0.4$ & $1.1 \pm 0.5$ & $1.2 \pm 0.3$ & 0.09 \\
\hline VP, $\mathrm{mmHg}$ & $5.3 \pm 1$ & $5.5 \pm 1$ & $4.3 \pm 1^{\#}$ & 0.01 \\
\hline \multicolumn{5}{|l|}{ Gas exchange responses } \\
\hline $\mathrm{SaO}_{2 \text { rest }}, \%$ & $96 \pm 1$ & $93 \pm 2^{*}$ & $95 \pm 2 \#$ & $<0.000$ \\
\hline $\mathrm{SaO}_{2 \text { peak }} \%$ & $94 \pm 3$ & $87 \pm 7^{*}$ & $94 \pm 3^{\#}$ & $<0.000$ \\
\hline \multicolumn{5}{|l|}{ Perception of symptoms } \\
\hline Peak dyspnea score, 0-10 & $4 \pm 3$ & $6 \pm 2^{*}$ & $6 \pm 2^{*}$ & 0.007 \\
\hline Peak leg effort score, $0-10$ & $4 \pm 3$ & $3 \pm 3$ & $6 \pm 3^{\#}$ & 0.03 \\
\hline \multicolumn{5}{|c|}{$\begin{array}{l}\text { Used ANOVA one way; HF: Heart Failure, COPD: Chronic Obstructive Pulmonary Disease; } \mathrm{VO}_{2}: \text { Oxygen } \\
\text { uptake; } \mathrm{VCO}_{2} \text { : Carbon dioxide output, RER: Respiratory exchange ratio; } \mathrm{HR} \text { : Heart rate, } \mathrm{SBP} \text { : Systolic } \\
\text { Blood Pressure, DBP: Diastolic Blood Pressure, RPP: rate-pressure product, } \mathrm{CP} \text { : circulatory power, VE: } \\
\text { Ventilation, MVV: Maximal Voluntary Ventilation, VE/VCO } 2 \text { slope: Linear relation between minute } \\
\text { ventilation and carbon dioxide output; OUES: Linear relationship between oxygen uptake and minute } \\
\text { ventilation, VP: Ventilatory Power; } \mathrm{SaO}_{2} \text { : peripheral saturation of } \mathrm{O}_{2} \text {. }\end{array}$} \\
\hline \multicolumn{5}{|c|}{ * Significant difference $(p<0.05)$ in relation to the HF group. } \\
\hline \multicolumn{5}{|c|}{ \# Significant difference $(p<0.05)$ in relation to the COPD group. } \\
\hline
\end{tabular}


The presence of hypoxemia on exertion, assessed by $\mathrm{SpO}_{2}$, did not differ between the HF and HF + COPD groups, but it was significantly reduced in the COPD group $(p<0.05)$. The subjective perception of exertion (i.e., dyspnea and fatigue in the legs) was higher in the COPD and HF + COPD groups, the main reason for the end of the test being dyspnea.

The HF group showed better cardiorespiratory fitness compared to the other groups when we evaluated different moments of the incremental exercise (Fig. 3). From rest to peak exercise, the increment in $\mathrm{VO}_{2}$ and TC were greater in the HF group compared to the COPD and HF + COPD groups.

\section{Relationships between measures of pulmonary function, anthropometric measures, clinical characteristics and exercise responses}

We found associations between components of pulmonary function, anthropometric measures, clinical characteristics and CPET variables (Figs. 4 and 5). Combining the three groups, significant correlations were observed between lean mass and peak $\mathrm{VO}_{2}$ ( $\left.\mathrm{r}: 0.56 \mathrm{p}<0.001\right)$, lean mass and OUES ( $\mathrm{r}: 0.42 \mathrm{p}<$ $0.001)$, lean mass and peak $\mathrm{O}_{2}$ pulse ( $\left.\mathrm{r}: 0.58 \mathrm{p}<0.001\right), \mathrm{D}_{\mathrm{LCO}}$ and $\mathrm{WR}(\mathrm{r}: 0.51 \mathrm{p}<0.001)$, and $\mathrm{D}_{\mathrm{LCO}}$ and VP (r: $0.40 \mathrm{p:}$ 0.002). In addition, we found that $\mathrm{FEV}_{1}$ was correlated with peak $\mathrm{VO}_{2}(\mathrm{r}: 0.52 ; \mathrm{p}<0.001)$ and peak WR (r: 0.62; $\mathrm{p}<0.001)$.

\section{Occurrence of cardiopulmonary events in the follow-up period}

In Table 3, we can see that the occurrence of the events obtained was not different between the groups. The Fig. 6 shows the Klapan-Meier analysis in both groups. No differences were found between groups in cardiopulmonary outcomes when evaluating disease exacerbations, hospitalizations for cardiopulmonary causes, acute myocardial infarction, stroke or cardiac/pulmonary surgery (Fig. 6A). Regarding the assessment of survival determined by the occurrence of deaths, we could observe no significant differences were found between the groups (Fig. 6B). 
Table 3

Occurrence of cardiopulmonary events during the follow-up period.

\begin{tabular}{|lllll|}
\hline Outcomes & HF & COPD & HF + COPD & $p$ \\
\hline Disease exacerbation, $\mathrm{n}(\%)$ & $\mathbf{n = 4 6}$ & $\mathbf{n = 5 3}$ & $\mathbf{n = 2 5}$ & \\
\hline AMI, $\mathrm{n}(\%)$ & $16(34.7)$ & $20(37.7)$ & $10(40)$ & 0.85 \\
\hline Stroke, $\mathrm{n}(\%)$ & $3(6.5)$ & $0(0)$ & $0(0)$ & 0.07 \\
\hline Hospitalization, $\mathrm{n}(\%)$ & $3(6.9)$ & $4(7.5)$ & $1(4)$ & 0.97 \\
\hline Death, $\mathrm{n}(\%)$ & $10(21.7)$ & $13(28.2)$ & $7(15.2)$ & 0.40 \\
\hline Others, $\mathrm{n}(\%)$ & $4(6.5)$ & $5(9.4)$ & $5(16)$ & 0.59 \\
\hline $\begin{array}{l}\text { AMl: acute myocardial infarction, Others: gastric or renal or intestinal surgery, decompensation of } \\
\text { non-cardiopulmonary diseases. }\end{array}$ & $9(19.6)$ & $4(7.5)$ & $1(4)$ & 0.07 \\
\hline
\end{tabular}

\section{Discussion}

The main original findings of the present investigation involving patients with HF, COPD and coexisting HF + COPD are as follows: 1 ) the prevalence of HF + COPD overlap was $20 \%$ in the studied population. 2) patients with $\mathrm{HF}+\mathrm{COPD}$ had the greatest impairment with cardiorespiratory fitness, expressed by lower values in key CPET variables; 3 ) when groups were contrasted at different distinct exercise time points, the HF group has better responses compared to the other two groups, including WR, peak $\mathrm{VO}_{2} ; 4$ ) correlations in the overall group suggest that components of pulmonary function and anthropometric characteristics can influence CPET variables; 5) after the follow-up period of both groups, no differences were found in the occurrence of cardiopulmonary events and deaths.

The aging population is a worldwide phenomenon; due to the health issues associated with aging, a higher proportion of the global population are at risk for chronic disease and diagnoses as well as comorbidity ${ }^{23}$. A coexistance of HF and COPD (overlap syndrome) has been associated with increased morbidity and decreased quality of life as well as a greater use of health resources; the literature indicates a HF + COPD prevalence between $10-30 \%{ }^{8}, 24,25$. Age, sex and anthropometric characteristics have been shown to influence cardiorespiratory fitness ${ }^{26}$. In our study, these factors were different between groups, being that the COPD and HF + COPD groups were older than the HF group $(p<0.05)$, moreover body composition was different between HF and COPD groups. These findings may indicate an advantage for this group, although the groups are in an age range between 60-70 years on average. These differences may explain the slightly more favorable exercise response in the HF group.

Left ventricular EF has been an important survival marker in patients with cardiopulmonary diseases. It has been shown that age has an influence on systolic function, and although differences in EF were not found between HF and HF + COPD, the mean age of the overlap group was higher. Shah et al. assessed 
18,398 subjects with reduced EF and found that the mean survival of patients aged 65-69 was 4 years ${ }^{27,28}$. In relation to pulmonary function, no differences were found between the two groups with COPD in spirometric values. Nevertheless, static lung values demonstrated that the COPD group presented with compatible volumes with greater air trapping, as expected, and a worse $D_{\text {LCO }}$. In general, inflammation and structural changes in the airways resulting from COPD increase expiratory flow limitations and worsens with advancing disease severity. This pathophysiologic manifestation is known related to the degree of limitations in performing activities of daily life and participation in leisure time physical activities ${ }^{29}$.

The association of comorbidities in individuals with cardiopulmonary diseases increases the risk of clinical events and mortality ${ }^{30}$. We found significant differences for the main evaluated comorbidities, specifically the HF group had higher mean values of comorbidities when compared to the COPD group. These comorbidities are risk factors for the development of cardiopulmonary disease and can often be the initial trigger or the aggravating etiological factor of the disease ${ }^{31}$.

It is already well known that patients with HF and COPD have reduced exercise performance, due to impaired ventilatory function and systemic manifestations that affect the muscular and cardiopulmonary system, increasing the limitation to exertion ${ }^{32,33}$. CPET allows a rigorous evaluation of the interaction between respiratory deficiencies caused by diseases and reduced exercise capacity in individuals under physiological stress, being possible to verify which is the main limiting factor to physical exercise ${ }^{34}$. Thus, in the present study, the HF + COPD group had a lower WR when compared to the HF group. The association between advanced age, intrapulmonary conditions, impaired cardiovascular function and loss of muscle strength and endurance in these patients leads to impaired performance during exercise, and intolerance to high workloads ${ }^{35,36}$. Peak $\mathrm{VO}_{2}$ is the main marker of aerobic capacity. In our study, we only found differences in absolute values; no differences were found for the relative values. $A$ combination of factors leads to a reduction in peak $\mathrm{VO}_{2}$ of patients with $\mathrm{HF}+\mathrm{COPD}$ : ventilatory abnormalities that generate inefficiency in capitation, changes in the heart pump that lead to impaired delivery, and changes in muscle cell composition that contribute to reduced oxygen utilization ${ }^{37,38}$.

A comprehensive assessment of several measures obtained from CPET provide for a more comprehensive cardiorespiratory fitness evaluation ${ }^{39}$. The $\mathrm{O}_{2}$ pulse is a strong predictor of disease severity and adverse events ${ }^{40}$. Mathematically, the $\mathrm{O}_{2}$ pulse is determined by the product of the stroke volume and arteriovenous oxygen difference, and changes in $\mathrm{O}_{2}$ pulse during exercise suggested alterations in the stroke volume ${ }^{41}$. In the current study, we observes that the HF group, when compared to the COPD group, have higher $\mathrm{O}_{2}$ pulse values. The RPP was significantly lower in the HF + COPD group when compared with the COPD group, indicating poorer cardiac function, as expected in this comorbidity group. The influence of HF in the group with overlap syndrome can increase myocardial oxygen consumption, leading to exhaustion of coronary blood flow reserve and impaired myocardial perfusion ${ }^{42}$. Another important variable that reflects central and peripheral components of cardiac work is CP. Our HF 
+ COPD group presented with worse CP values, this can be explained by the fact that the association of the two diseases leads to reduced cardiac function, which during high-intensity exercise can lead to pulmonary congestion, and that, associated with higher pulmonary arterial pressure and pulmonary vascular resistance, increases ventilation-perfusion incompatibility, producing ventilatory inefficiency and contributing to low $\mathrm{CP}$ values ${ }^{43}$.

In recent years, more complex variables derived from CPET have proved to be strong prognostic variables, capable of providing complementary and superior information compared to the isolated use of peak $\mathrm{VO}_{2}$ 44 . In our study, no differences were found for the $V_{\mathrm{E}} / \mathrm{VCO}_{2}$ slope, although all groups demonstrated a mean value above the normal threshold (i.e., >30), thus observing a worse prognosis for these patients. Guazzi et al followed 213 cardiac patients and found that $\mathrm{V}_{\mathrm{E}} / \mathrm{VCO}_{2}$ slope values $\geq 34$ associated with $\mathrm{VO}_{2}$ peak $\leq 14 \mathrm{ml} \cdot \mathrm{kg}^{-1} \cdot \mathrm{min}^{-1}$ were strong predictors of hospitalization and mortality ${ }^{45}$.

The $\mathrm{V}_{\mathrm{E}} / \mathrm{VCO}_{2}$ intercept is a new parameter, and in patients with lung diseases it increases with the severity of disease ${ }^{46}$. Surprisingly, only the COPD group had higher values of $\mathrm{V}_{\mathrm{E}} / \mathrm{VCO}_{2}$ intercept, suggesting an increased dead space on exercise, something that was not seen in our overlap group. Nevertheless, HF + COPD presented reduced VP in comparison with HF group $(p<0.05)$. The VP has been studied as a prognostic marker in cardiopulmonary diseases ${ }^{47,48}$. This variable reflects peak cardiac output, alveolar perfusion, peripheral perfusion and the chemo-afferent reflexes of the skeletal muscle, with values below $3.5 \mathrm{mmHg}$ indicating worsening survival ${ }^{21}$.

Pulmonary and systemic cardiocirculatory maladjustments occur in both HF and COPD and in individuals with overlap, these effects are more prominent. Muscle weakness is the most common systemic effect, as it occurs in chronic processes such as what occurs in both diseases. The systemic effects of these diseases directly affect the ventilatory function, which manifest a pronounced intolerance to exercise, worse health status and higher mortality ${ }^{49,50}$. In the current study, the HF + COPD group had worse perception of symptoms, when compared to the HF group; the perception of dyspnea was higher, and when compared to the COPD group, fatigue values were higher $(p<0.05)$.

The HF group presented with better responses to incremental exercise when contrasted with the COPD and HF + COPD groups (Fig. 3). We believe that the fact that the HF group is composed of the majority of patients with mild staging reflected better physiological adjustments to exercise, furthermore, the association between advanced age, intrapulmonary conditions, impaired cardiovascular function (that even in COPD is present) and loss of muscle strength and endurance in COPD and HF + COPD patients leads to further deterioration cardiorespiratory fitness, making these patients not tolerate high workloads and present with a poorer exercise performance ${ }^{51,36}$.

Important correlations between clinical variables, body composition and CPET variables were found in this study. It is important to note that lean mass moderately influenced peak $\mathrm{VO}_{2}$, OUES and $\mathrm{O}_{2}$ pulse responses in the patients studied. An adequate interaction between the ventilatory, cardiovascular and 
muscular systems is a determining factor for appropriate oxygen metabolism during incremental exercise. Cardiopulmonary disease initially leads to a compromise of the pulmonary and cardiovascular systems, however, with disease progression, lean mass alterations occur in these populations affecting muscle performance during exercise. These changes occur due factors such as hypoxia, oxidative stress, disuse, nutritional depletion, systemic inflammation and changes in muscle morphology, fiber type distribution and metabolism ${ }^{52}$. Other important findings correlate $\mathrm{D}_{\mathrm{LCO}}$, and $\mathrm{FEV}_{1}$ with peak $\mathrm{VO}_{2}$, WR and VP. Impaired lung function due to air flow limitations, increased intrathoracic pressures, increased intrathoracic blood volume and chronic pulmonary congestion and accumulation of extravascular lung water has a direct effect on the cardiopulmonary response to exercise, leading to increased pulmonary ventilation, ventilatory inefficiency and, consequently, low peak $\mathrm{VO}_{2}$ and $\mathrm{WR}^{8,53}$.

Surprisingly, we found no differences between the outcomes assessed in the follow-up of patients in both groups. Although the HF + COPD group has a greater impairment of cardiorespiratory fitness, it is possible to note that the HF and COPD groups also present values of key cardiopulmonary variables for the studied populations compatible with a worse prognosis and high risk of adverse events in the period from 1 to 4 years of follow-up ${ }^{54}$. Furthermore, advances in the clinical treatment of both diseases together with greater access to cardiopulmonary rehabilitation have favored better control of the progress of these diseases $^{55}$.

\section{Study Limitations}

This study has some limitations which are inherent to its nature that consider the screening of patients at two ambulatory clinics (pneumology and cardiology) diagnosed with at least one of the diseases and aged over 50 years. As the purpose of the present study was to evaluate the coexistence of one condition in the other, it would be expected that some clinical variables would be different. In this context, the absence of female individuals in the HF + COPD group and the difference of age between groups can influence the CPET response. However, to mitigate this bias, knowing that some variables could be influenced by age and sex, we performed a linear regression analysis to verify the influence on CPET variables that differed. We verified that age and sex had weak but significant influence on WR $\left(R^{2}: 0.22 \mathrm{p}\right.$ : $0.000)$, absolute peak $V_{2} \mathrm{O}_{2}\left(\mathrm{R}^{2}: 0.25 \mathrm{p}: 0.000\right), \mathrm{O}_{2}$ pulse $\left(\mathrm{R}^{2}: 0.20 \mathrm{p}: 0.000\right)$ and $\mathrm{CP}\left(\mathrm{R}^{2}: 0.09 \mathrm{p}: 0.02\right)$.

\section{Conclusions}

In conclusion, the coexistence of HF+COPD induces greater impairment on exercise performance when compared to patients without overlapping diseases, however the overlap of the two diseases did not increase the probability of the occurrence of cardiopulmonary events and deaths when compared to groups with isolated diseases in the period studied. CPET provides important information to guide effective strategies for these patients with the goal of improving exercise performance and functional capacity. Moreover, given our findings related to pulmonary function, body composition and exercise responses, evidenced that the lean mass, $\mathrm{FEV}_{1}$ and $\mathrm{D}_{\mathrm{LCO}}$ influence important responses to exercise. 


\section{Declarations}

\section{ACKNOWLEDGEMENT OF GRANT SUPPORT:}

We would like to thank the Fundação de Amparo a Pesquisa do Estado de São Paulo (FAPESP) and the Coordenação de Apoio a Pessoal do Ensino Superior (CAPES) for providing financial support, allowing this work to be carried out. We extend our gratitude to the University Hospital of the Federal University of São Carlos for supporting patient recruitment for this study. Borghi-Silva A is an Established Investigator (level IB) of the Conselho Nacional de Desenvolvimento Científico e Tecnológico, Brazil. We are also grateful to all physical therapy team for technical support. More importantly, however, we are indebted to the patients for their effort and enthusiastic cooperation throughout the study.

\section{DISCLOSURE:}

The authors report no relationships that could be construed as a conflict of interest.

\section{CREDIT AUTHORSHIP CONTRIBUTION STATEMENT:}

All authors made substantial contributions to conception and design, acquisition of data, or analysis and interpretation of data; took part in drafting the article or revising it critically for important intellectual content; agreed to submit to the current journal; gave final approval of the version to be published; and agree to be accountable for all aspects of the work.

\section{References}

1. Vetrano, D. L. et al. ;. Frailty and Multimorbidity: A Systematic Review and Meta-analysis. J Gerontol A Biol Sci Med Sci. 2019 Apr 23;74(5):659-666.

2. World Health Organization. Cardiovascular disease. Accessed on 6/6/11; Available from: http://www.who.int/mediacentre/factsheets/ fs317/en/index.html.

3. Go, A. S. et al. ;. Heart disease and stroke statistics-2014 update: a report from the American Heart Association. Circulation. 2014 Jan 21;129(3):e28-e292.

4. Vestbo, J. et al. Global strategy for the diagnosis, management, and prevention of chronic obstructive pulmonary disease: GOLD executive summary. Am J Respir Crit Care Med, 15 (4), 347365 (2013 Feb).

5. Bleumink, G. S. et al. Quantifying the heart failure epidemic: prevalence, incidence rate, lifetime risk and prognosis of heart failure The Rotterdam Study. Eur Heart J, 25 (18), 1614-1619 (2004 Sep).

6. Liu, L. \& Eisen, H. J. Epidemiology of heart failure and scope of the problem.Cardiol Clin. 2014Feb;32(1):1-8, vii. 
7. Dumitru, L. et al. Disability in COPD and Chronic Heart Failure Is the Skeletal Muscle the Final Common Pathway? Maedica (Bucur). 2013 Jun;8(2):206-13.

8. Neder, J. A., Rocha, A., Berton, D. C. \& O'Donnell, D. E. Clinical and Physiologic Implications of Negative Cardiopulmonary Interactions in Coexisting Chronic Obstructive Pulmonary Disease-Heart Failure. Clin Chest Med, 40 (2), 421-438 (2019 Jun).

9. Wagner, P. D. Chronic Cardiopulmonary Disease and the Skeletal Muscle. Respir Care2006:37-40

10. Neder, J. A. et al. Current challenges in managing comorbid heart failure and COPD. Expert Rev Cardiovasc Ther, 16 (9), 653-673 (2018 Sep).

11. Ross, R. et al. ; ; Council on Cardiovascular and Stroke Nursing; Council on Functional Genomics and Translational Biology; Stroke Council. Importance of Assessing Cardiorespiratory Fitness in Clinical Practice: A Case for Fitness as a Clinical Vital Sign: A Scientific Statement From the American Heart Association. Circulation. 2016 Dec 13;134(24):e653-e699.

12. Nelson, N. \& Asplund, C. A. Exercise Testing: Who, When, and Why? PM R. 2016 Mar;8(3 Suppl):S1623.

13. von Elm, E. et al. ;. The Strengthening the Reporting of Observational Studies in Epidemiology (STROBE) statement: guidelines for reporting observational studies.J Clin Epidemiol. 2008Apr;61(4):344-9.

14. Lang, R. M. et al. Recommendations for cardiac chamber quantification by echocardiography in adults: an update from the American Society of Echocardiography and the European Association of Cardiovascular Imaging. J Am Soc Echocardiogr, 28 (1), 1-3914 (2015 Jan).

15. Global Initiative for Chronic Obstructive Lung Disease. Global strategy for the diagnosis, management, and prevention of chronic obstructive pulmonary disease. Chronic Respir Dis, 1, 1-141 (2020).

16. Borg, G. A. Psychophysical bases of perceived exertion. Med Sci Sports Exerc, 14 (5), 377-381 (1982).

17. Balady, G. J. et al. Council on Peripheral Vascular Disease; Interdisciplinary Council on Quality of Care and Outcomes Research. Clinician's Guide to cardiopulmonary exercise testing in adults: a scientific statement from the American Heart Association., 13 (2), 191-225 (2010 Jul).

18. Arena, R., Myers, J., Aslam, S. S., Varughese, E. B. \& Peberdy, M. A. Technical considerations related to the minute ventilation/carbon dioxide output slope in patients with heart failure., 124 (2), $720-727$ (2003 Aug).

19. Baba, R. et al. Oxygen uptake efficiency slope: a new index of cardiorespiratory functional reserve derived from the relation between oxygen uptake and minute ventilation during incremental exercise. J Am Coll Cardiol, 15 (6), 1567-1572 (1996 Nov).

20. Cohen-Solal, A. et al. A non-invasively determined surrogate of cardiac power ('circulatory power') at peak exercise is a powerful prognostic factor in chronic heart failure. Eur Heart J, 23 (10), 806-814 (2002 May). 
21. Forman, D. E. et al. Ventilatory power: a novel index that enhances prognostic assessment of patients with heart failure. Circ Heart Fail. 2012 Sep 1;5(5):621-6.

22. Hinkle, D. E., Wiersma, W. \& Jurs, S. G. Applied Statistics for the Behavioral Sciences 5th edn (Houghton Mifflin, Boston, 2003).

23. Gijsen, R. et al. Causes and consequences of comorbidity: a review. J Clin Epidemiol, 54 (7), 661-674 (2001 Jul).

24. Macchia, A. et al. Unrecognised ventricular dysfunction in COPD. Eur Respir J, 39 (1), 51-58 (2012 Jan).

25. de Miguel Díez, J., Chancafe Morgan, J. \& Jiménez García, R. The association between COPD and heart failure risk: a review. Int J Chron Obstruct Pulmon Dis, 8, 305-312 (2013).

26. Neder, J. A. et al. Prediction of metabolic and cardiopulmonary responses to maximum cycle ergometry: a randomised study. Eur Respir J, 14 (6), 1304-1313 (1999 Dec).

27. Lakatta, E. G. \& Levy, D. Arterial and cardiac aging: major shareholders in cardiovascular disease enterprises: Part II: the aging heart in health: links to heart disease. Circulation. 2003 Jan 21;107(2):346 - 54.

28. Shah, K. S. et al. Heart Failure With Preserved, Borderline, and Reduced Ejection Fraction: 5-Year Outcomes. J Am Coll Cardiol, 14 (20), 2476-2486 (2017 Nov).

29. Barnes, P. J. Inflammatory mechanisms in patients with chronic obstructive pulmonary disease. $J$ Allergy Clin Immunol, 138 (1), 16-27 (2016 Jul).

30. Manuel, D. G., Schultz, S. E. \& Kopec, J. A. Measuring the health burden of chronic disease and injury using health adjusted life expectancy and the Health Utilities Index. J Epidemiol Community Health, 56 (11), 843-850 (2002).

31. Mosterd, A. \& Hoes, A. W. Clinical epidemiology of heart failure.Heart. 2007Sep;93(9):1137-46.

32. Güder, G. \& Rutten, F. H. Comorbidity of heart failure and chronic obstructive pulmonary disease: more than coincidence. Curr Heart Fail Rep, 11 (3), 337-346 (2014 Sep).

33. Hawkins, N. M., Virani, S. \& Ceconi, C. Heart failure and chronic obstructive pulmonary disease: the challenges facing physicians and health services. Eur Heart J, 34 (36), 2795-2803 (2013 Sep).

34. Ingle, L. Theoretical rationale and practical recommendations for cardiopulmonary exercise testing in patients with chronic heart failure. Heart Fail Rev, 12 (1), 12-22 (2007 Mar).

35. Steinborn, W. \& Anker, S. Cardiac cachexia: pathophysiology and clinical implications. Basic Appl Myol, 13, 191-201 (2003).

36. Agustí, A. G. et al. Systemic effects of chronic obstructive pulmonary disease. Eur Respir J, 21 (2), 347-360 (2003 Feb).

37. Agostoni, P., Cattadori, G., Bussotti, M. \& Apostolo, A. Cardiopulmonary interaction in heart failure. Pulm Pharmacol Ther, 20 (2), 130-134 https://doi.org/10.1016/j.pupt.2006.03.001 (2007).

38. Arena, R. \& Sietsema, K. E. Cardiopulmonary exercise testing in the clinical evaluation of patients with heart and lung disease., 15 (6), 668-680 (2011 Feb). 
39. Guazzi, M. et al. 2016 focused update: clinical recommendations for cardiopulmonary exercise testing data assessment in specific patient populations. Eur Heart J. 2018 Apr 7;39(14):1144-1161. doi: 10.1093/eurheartj/ehw180.

40. Bhambhani, Y., Norris, S. \& Bell, G. Prediction of stroke volume from oxygen pulse measurements in untrained and trained men. Can J Appl Physiol, 19 (1), 49-59 (1994 Mar).

41. Mahler, D. A., Parker, H. W. \& Andresen, D. C. Physiologic changes in rowing performance associated with training in collegiate women rowers. Int J Sports Med, 6 (4), 229-233 (1985 Aug).

42. Dini, F. L. et al. Coronary flow reserve in idiopathic dilated cardiomyopathy: relation with left ventricular wall stress, natriuretic peptides, and endothelial dysfunction. J Am Soc Echocardiogr, 22 (4), 354-360 (2009 Apr).

43. Witte, K. K. \& Clark, A. L. Why does chronic heart failure cause breathlessness and fatigue? Progress in Cardiovascular Diseases, 49, 366-384 (2007).

44. Arena, R., Myers, J. \& Guazzi, M. Cardiopulmonary exercise testing is a core assessment for patients with heart failure. Congest Heart Fail, 17 (3), 115-119 (2011 May-Jun).

45. Arena, R., Myers, J., Aslam, S. S., Varughese, E. B. \& Peberdy, M. A. Peak VO2 and VE/VCO2 slope in patients with heart failure: a prognostic comparison. Am Heart J, 147 (2), 354-360 (2004 Feb).

46. Apostolo, A. et al. Impact of chronic obstructive pulmonary disease on exercise ventilatory efficiency in heart failure. Int J Cardiol, 189, 134-140 (2015).

47. Goulart, C. D. L. et al. The Value of Cardiopulmonary Exercise Testing in Determining Severity in Patients with both Systolic Heart Failure and COPD. Sci Rep. 2020 Mar 9;10(1):4309.

48. Dos Santos, P. B. et al. Eccentric Left Ventricular Hypertrophy and Left and Right Cardiac Function in Chronic Heart Failure with or without Coexisting COPD: Impact on Exercise Performance.Int J Chron Obstruct Pulmon Dis. 2021 Feb3;16:203-214.

49. Montes de Oca, M. et al. Peripheral muscle composition and health status in patients with COPD. Respir Med, 100 (10), 1800-1806 (2006 Oct).

50. Buller, N. P., Jones, D. \& Poole-Wilson, P. A. Direct measurement of skeletal muscle fatigue in patients with chronic heart failure. Br Heart J, 65 (1), 20-24 (1991 Jan).

51. Steinborn, W. \& Anker, S. Cardiac cachexia: pathophysiology and clinical implications. Basic Appl Myol, 13, 191-201 (2003).

52. Gosker, H. R., Wouters, E. F., van der Vusse, G. J. \& Schols, A. M. Skeletal muscle dysfunction in chronic obstructive pulmonary disease and chronic heart failure: underlying mechanisms and therapy perspectives. Am J Clin Nutr, 71 (5), 1033-1047 (2000 May).

53. Alencar, M. C. et al. Does Exercise Ventilatory Inefficiency Predict Poor Outcome in Heart Failure Patients With COPD? J Cardiopulm Rehabil Prev, 36 (6), 454-459 (2016 Nov/Dec).

54. Guazzi, M. et al. 2016 focused update: Clinical recommendations for cardiopulmonary exercise testing data assessment in specific patient populations.Circulation. 2016. 
55. World Health Organization. Innovative care for chronic conditions: building blocks for action (WHO, Geneva, Switzerland, 2012). [2016-09-21].

\section{Figures}

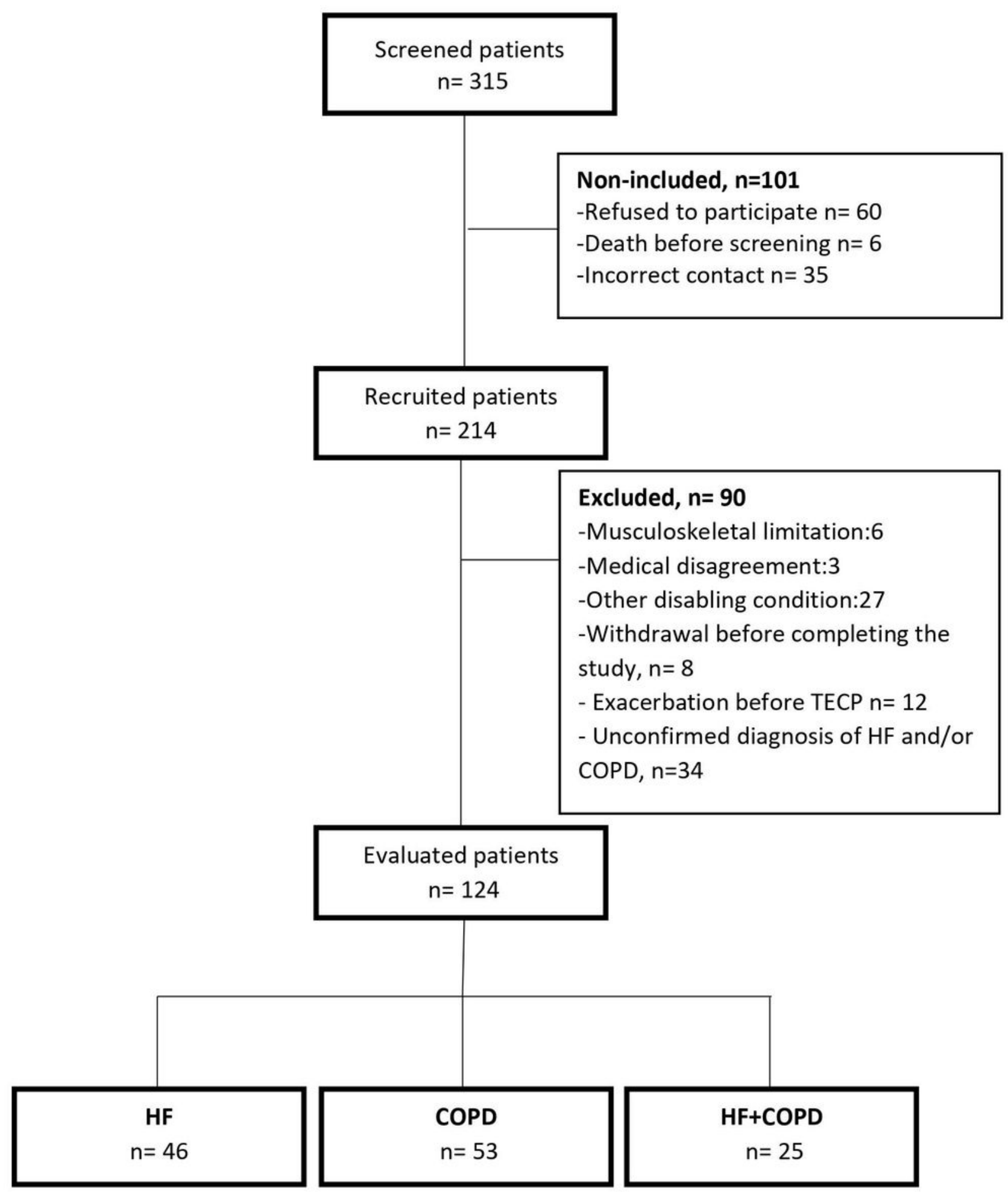

Figure 1 


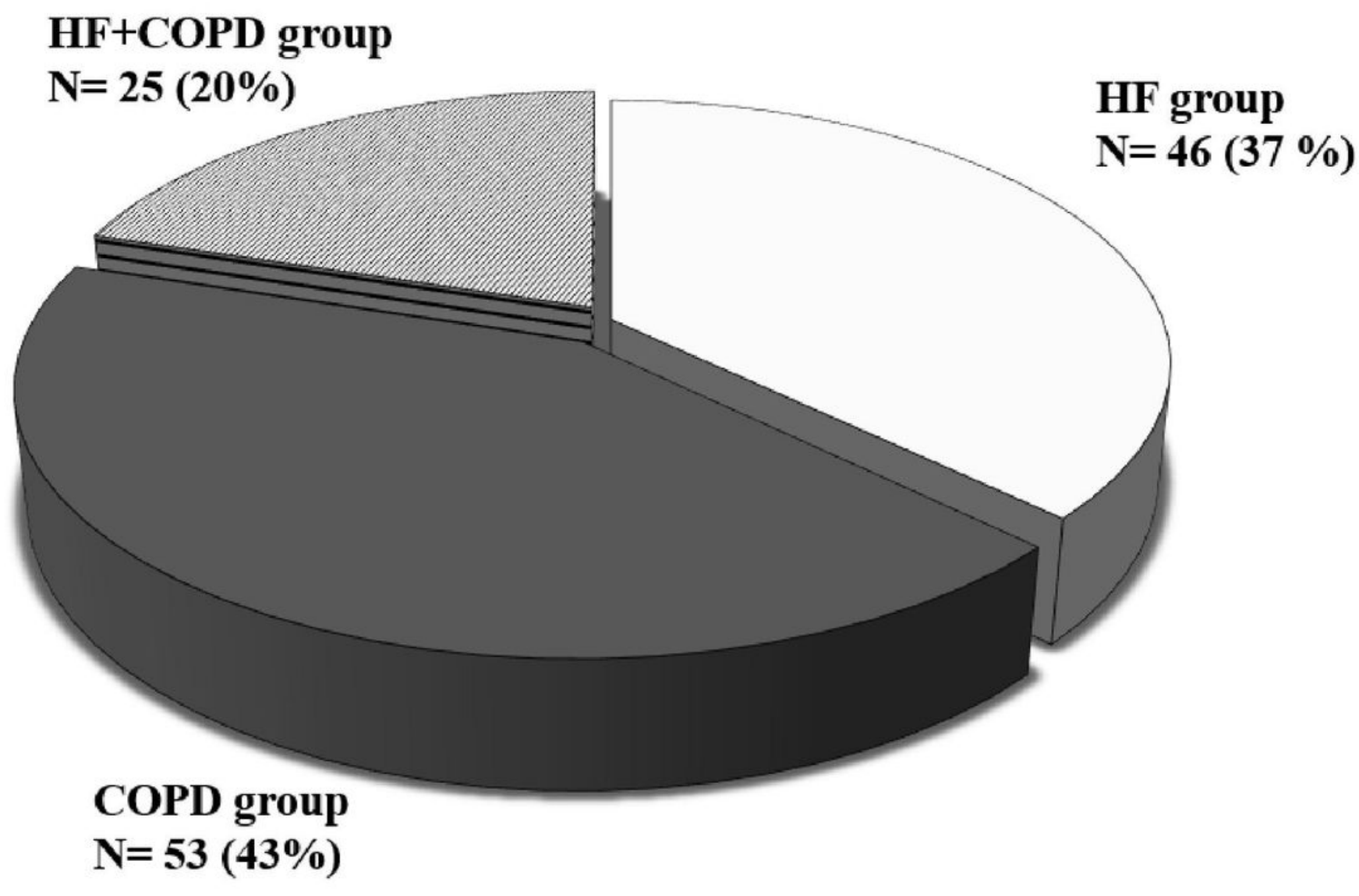

$\square \mathrm{HF} \square \mathrm{COPD} \square \mathrm{HF}+\mathrm{COPD}$

Figure 2

Prevalence of patients with HF+COPD overlap in studied populations. HF: heart failure, COPD: Chronic Obstructive Pulmonary Disease 

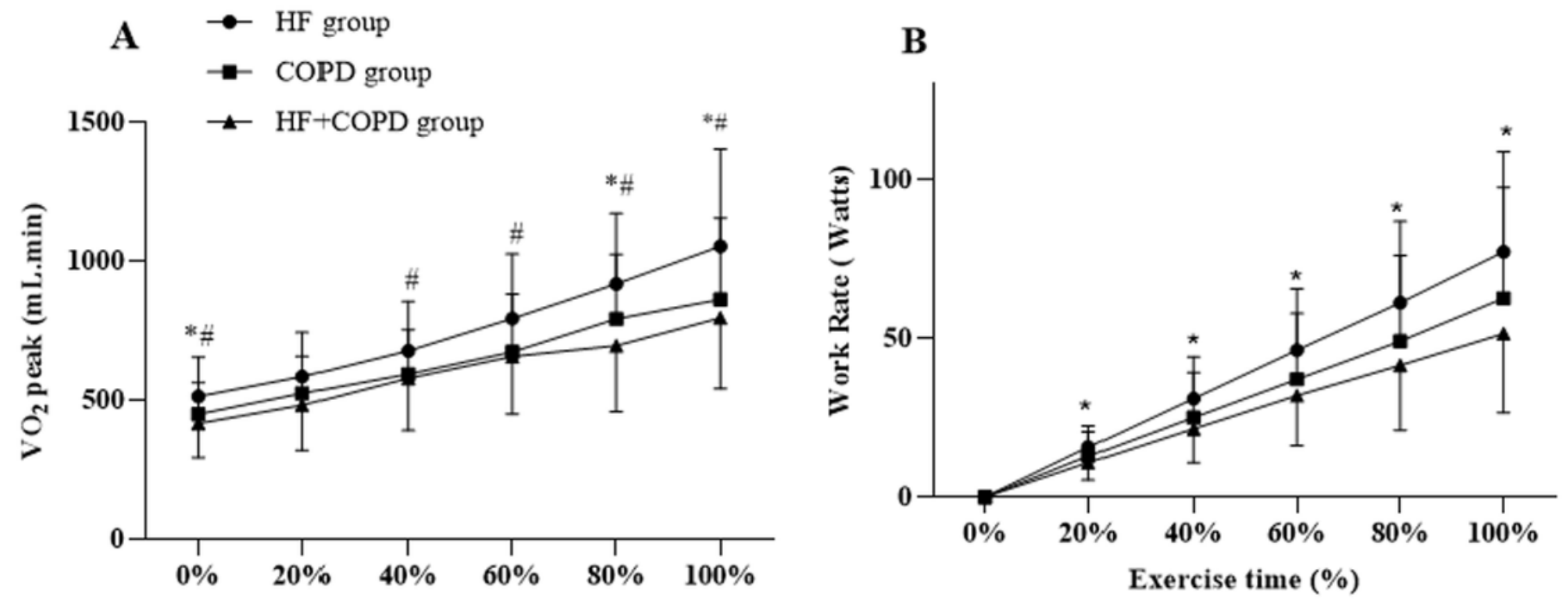

Figure 3

Behavior of VO2 and WR between groups during exercise time. * Significant difference $(p<0.05)$ in relation to the HF with HF+COPD, \# Significant difference $(p<0.05)$ in relation to the HF with COPD.
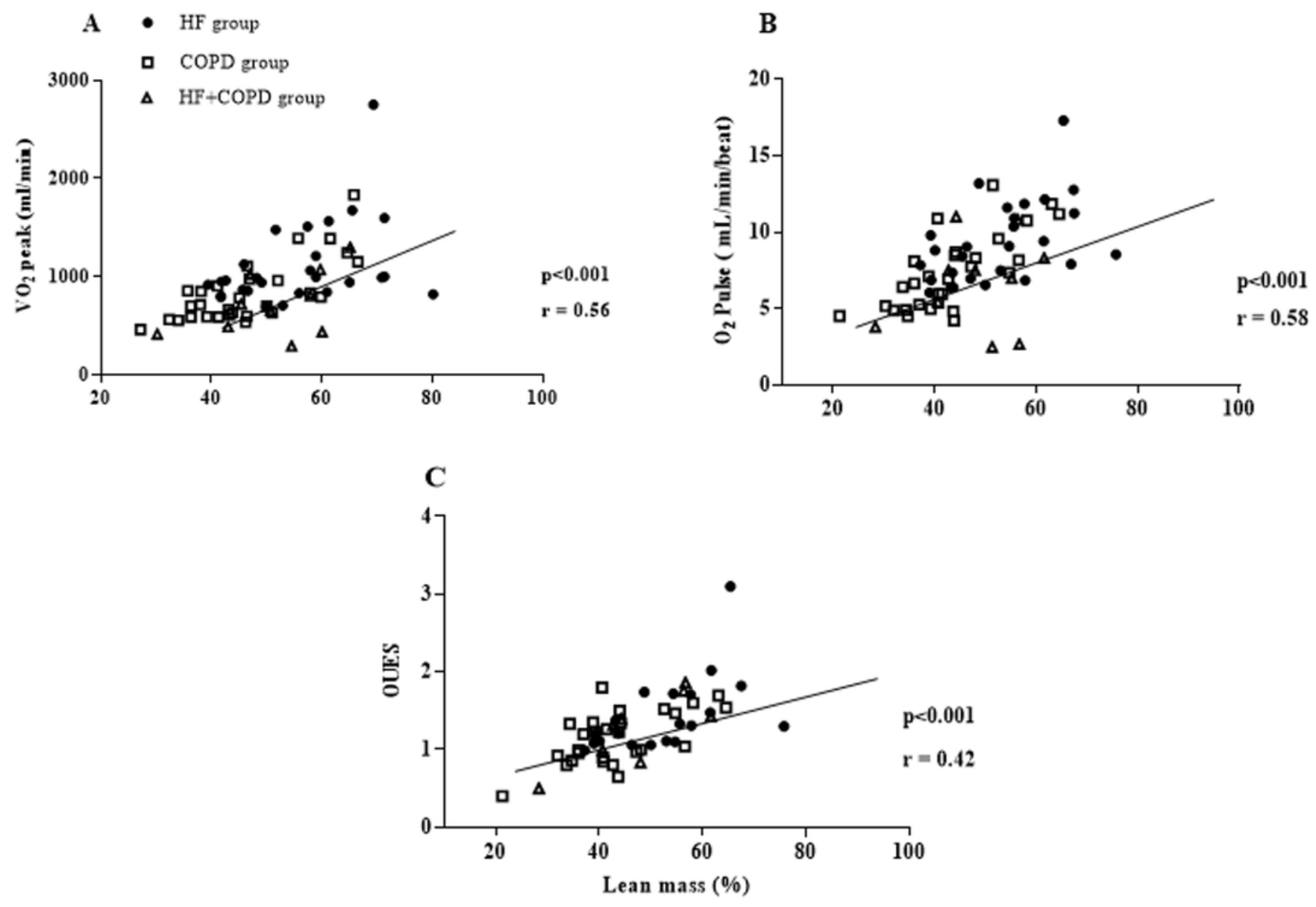
Figure 4

Correlation between body composition and CPET responses; Used Pearson correlation coefficient. A: Relationship between lean mass and oxygen uptake (VO2); B: Relationship between lean mass and Oxygen pulse; C: Relationship between lean mass and oxygen uptake efficiency slope.
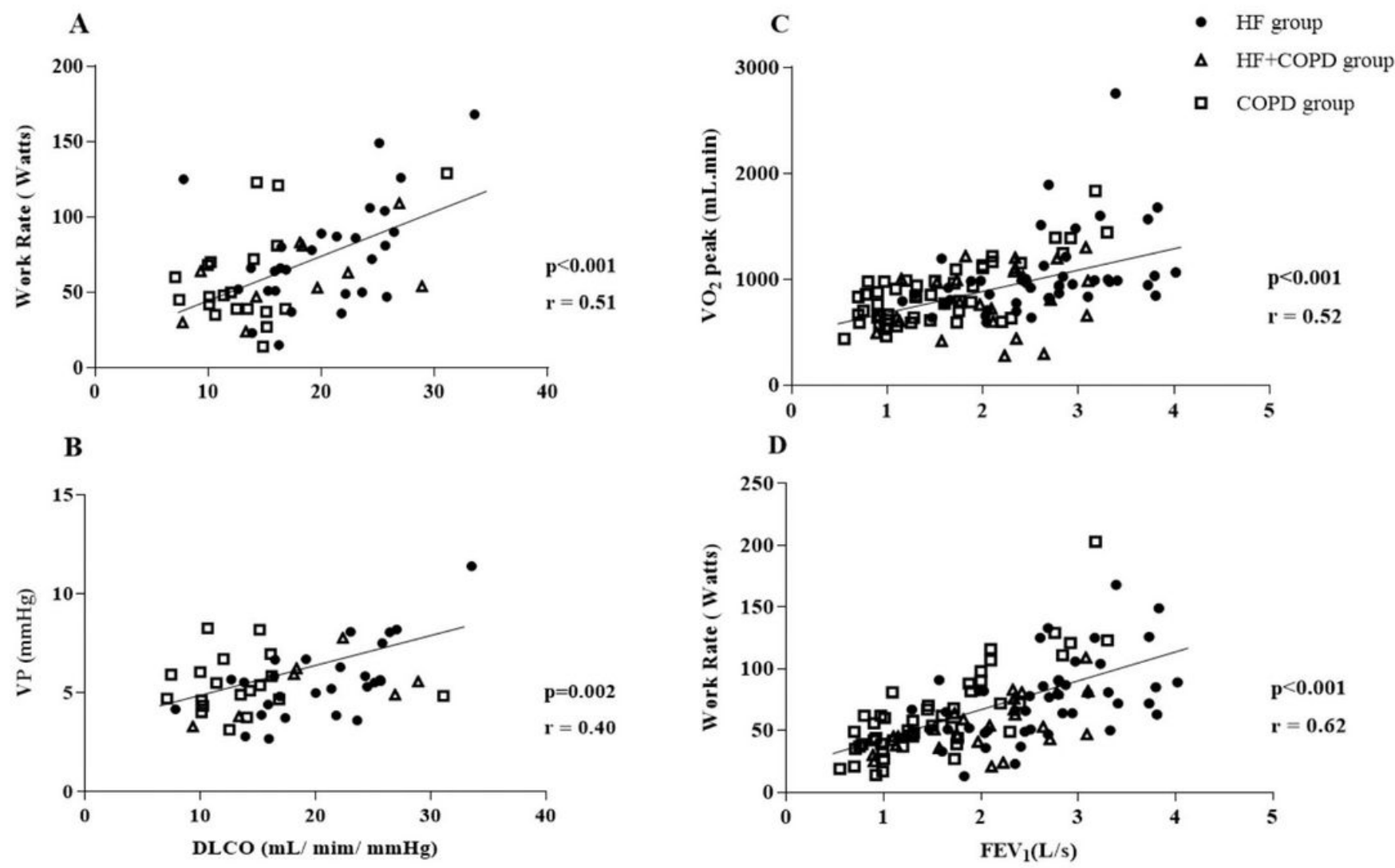

\section{Figure 5}

Correlation between lung function and CPET responses; Used Pearson correlation coefficient. A:

Relationship between diffusion capacity carbon monoxide (DLCO) and work rate; B: Relationship between DLCO and ventilatory power; C: Relationship between forced expiratory volume in the first second (FEV1) and peak oxygen uptake (VO2); D: Relationship between FEV1 and peak work rate. Patients that pefromed DLCO: 58 (HF:28, COPD:20, HF+COPD:10) 
A

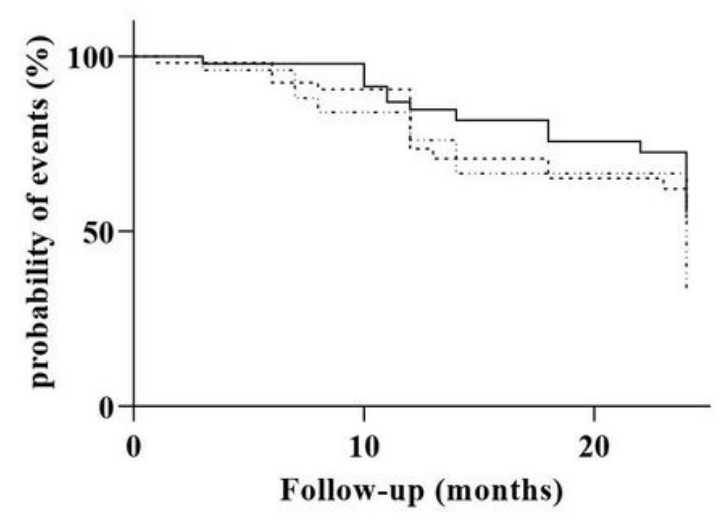

B $\quad p: 0.39$

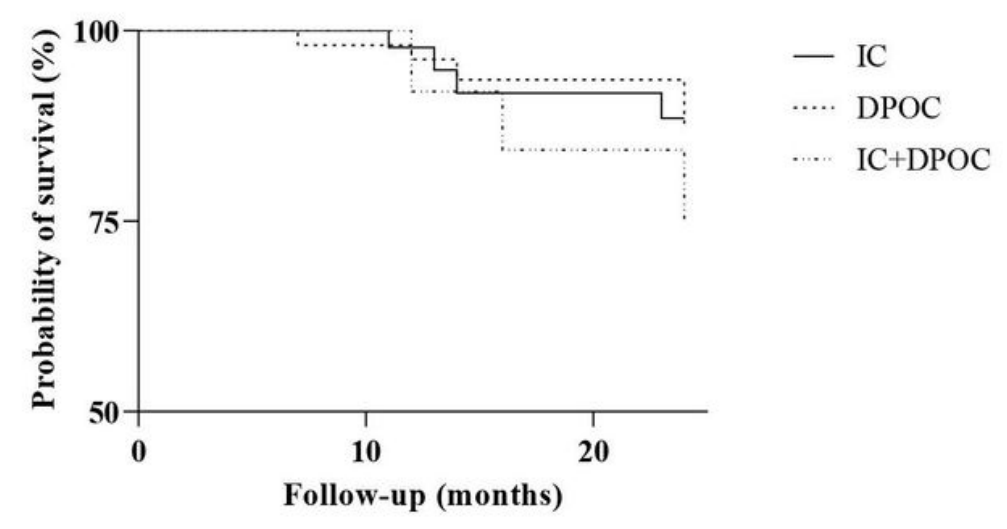

Figure 6

Kaplan-Meier curve. A: probability of occurrence of cardiopulmonary events; B: probability of survival assessed by occurrence of deaths. 